\title{
Gender-specific benefits of eating eggs at resident reef fish spawning aggregation sites
}

\author{
Matthew R. Fraser, Mark I. McCormick* \\ ARC Centre of Excellence for Coral Reef Studies, and School of Marine and Tropical Biology, James Cook University, \\ Townsville, Queensland 4811, Australia
}

\begin{abstract}
Food resource availability has a fundamental role in shaping consumer populations through changes in energy intake. Tropical reef fish spawning aggregations provide a resource pulse for reef-based planktonic egg predators, and an opportunity to quantify the energetic repercussions of natural changes in food availability in tropical reef fishes. We examined the effects of the consumption of eggs from the broadcast spawning surgeonfish Ctenochaetus striatus on the allocation of energy to body condition, growth and reproduction in the planktivorous egg-predator damselfish Abudefduf vaigiensis. Fish that fed on eggs at resident fish spawning aggregation sites (FSASs) had significantly greater lipid storage in liver vacuoles compared to conspecifics from non-FSASs. Growth of male A. vaigiensis was faster at FSASs than non-FSASs. However, we found no differences in the growth of females among sites. Female $A$. vaigiensis from FSASs invested more into reproduction, having larger gonadosomatic indices (GSI) than females from nonFSASs, while there was no difference in the GSI of males among FSASs and non-FSASs. At the same locations, no differences were found in the life-history traits of the reference species, Pomacentrus moluccensis, which does not consume eggs. This study demonstrates the role of natural variations in food availability on energetic processes in reef fish. Furthermore, the sex-specific energy allocation strategy highlights the complexity of the interaction between natural variations in food availability and life-history strategies. This study demonstrates that the conservation of FSASs may also benefit trophically linked reef fishes.
\end{abstract}

KEY WORDS: Fish spawning - Spawning aggregation · Egg mortality · Egg predation • Prey switching $\cdot$ Maternal effects $\cdot$ Fecundity $\cdot$ Trophic ecology $\cdot$ Reef fish condition

Resale or republication not permitted without written consent of the publisher

\section{INTRODUCTION}

Temporal variations in prey availability have a fundamental influence on predator population dynamics (Krebs 1994). Populations will respond energetically to temporal increases in prey availability by modifying their allocation of energy to life-history traits (May 1972). As such, individuals are expected to allocate energy to growth, condition and reproduction according to their life-history strategy that has evolved to maximise reproductive success over an individual's expected life span (Stearns 1992). To understand processes that govern population dynamics, it is essential to understand the relationship between temporal pulses in natural food availability and trade-offs in energy allocation to life-history traits.

Evidence suggests that food is a limited resource for reef fishes in tropical marine waters (Forrester 1990, Jones \& McCormick 2002). Manipulative experiments that artificially increased food availability to reef fishes showed that growth, both in juveniles (Jones 1986) and adults (Jones \& McCormick 2002), and reproduction are tightly regulated by food availability (McCormick 2003). Because sexual maturity (Roff 1984) and mortality schedules (Gust et al. 2002) are related to size in fishes, energy allocated to 
growth from increased food availability can also increase the size of a breeding population (Jones \& McCormick 2002). However, in tropical reef fishes, little is known of the trade-offs in energy allocation to growth and reproduction in response to natural fluctuations in food availability (but see Clifton 1995). Jones (1986) highlighted the need to examine the response of demographic parameters in reef fishes to natural variations in preferred prey items. After almost 3 decades of subsequent research, few studies have addressed this paucity of knowledge, possibly due to the logistical difficulty of testing natural variations in food availability with appropriate controls. However, the study of natural pulses in food availability provides a unique opportunity to examine how reef fishes make trade-offs in energy allocation to growth and reproduction.

Many reef-associated fishes aggregate to spawn, and this provides a pulse of energy-rich eggs to planktivorous egg predators (Sancho et al. 2000, Nemeth 2012, Pears et al. 2012, Claydon et al. 2014). In the tropics, over 100 species from some 18 families have been found to spawn at highly localised fish spawning aggregation sites (FSASs; Domeier \& Colin 1997, Claydon 2004, Claydon et al. 2014), most of which broadcast spawn their gametes above the reef. At these sites, breeding groups make rapid spawning rushes toward the water's surface to release their gametes into the prevailing current. At the apex of spawning rushes where visible gamete clouds are released, eggs are at much higher densities than alternative planktonic prey. Recently spawned eggs also have 20 to $25 \%$ greater energy content than other plankton (Kamler 1992). Planktonic eggs from a range of vertebrate and invertebrate marine taxa usually form a small portion of a tropical planktivorous fish's diet (Sano et al. 1984). However, egg predators aggregate to feed on spawners' gamete clouds at FSASs (e.g. Sancho et al. 2000). Therefore, it may be expected that eggs released at FSASs represent a valuable prey source with the potential to influence the life-history processes of egg predators. Analysis of how egg predators allocate energy in response to this natural pulse in egg abundance provides a unique opportunity to analyse energy partitioning in reef fish under natural conditions.

The aim of this study was to determine whether feeding on eggs at reef FSASs influenced the lifehistory traits of a key egg predator, the damselfish Abudefduf vaigiensis. Specifically, we examined how this predator of nutrient-rich eggs allocated energy to growth, body condition and reproduction, and whether this was affected by gender.

\section{MATERIALS AND METHODS}

\section{Study site and species}

This study was conducted in Kimbe Bay, West New Britain Province, Papua New Guinea $\left(5^{\circ} 30^{\prime} \mathrm{S}\right.$, $150^{\circ} 05^{\prime} \mathrm{E}$ ), on 2 small inshore platform reefs (Hanging Gardens and Limuka). The reefs were steepsided platform reefs, less than $1 \mathrm{~km}$ from shore, $800 \mathrm{~m}$ apart and separated by deep passages of water ( $>50 \mathrm{~m}$ deep), which made migration of small reef fishes between adjacent reefs unlikely (see Fig. 3 in Claydon et al. 2014). Sampling was conducted at 2 FSASs and 1 non-FSAS on Hanging Gardens Reef, and 1 FSAS and 1 non-FSAS on Limuka Reef. NonFSASs were locations on the reef where reef fish spawning had never been observed but were of a similar size, aspect to the open ocean, coral cover and topographic complexity, and were over $100 \mathrm{~m}$ from FSASs.

At the studied FSASs, the shallow-dwelling surgeonfish Ctenochaetus striatus is known to form large spawning aggregations (up to 2000 individuals) a maximum of once per day per FSAS between 13:30 $\mathrm{h}$ and dusk ( 18:00 $\mathrm{h}_{\text {; }}$ Claydon et al. 2012). Spawning events by C. striatus are typified by $1 \mathrm{~h}$ of pre-spawning courting behaviour, followed by 10 to 15 min of intense synchronised spawning rushes that release visible gamete clouds near the water's surface (Randall 1961). Sampling of visible gamete clouds within $3 \mathrm{~s}$ of spawning using a $100 \mu \mathrm{m}$ mesh plankton net found that on average, $1.24 \mathrm{l} \mathrm{of} \mathrm{eggs} \mathrm{are}$ released during a $C$. striatus spawning aggregation (Fraser 2010). FSASs used by C. striatus at this study location were identified initially in 2001 (Claydon 2005) and were still in use in March 2008, 7 yr later. In Papua New Guinea, as in many places around the tropical Pacific, C. striatus is a preferred prey species of spear-fishers, and its densities respond rapidly to the establishment of no-take marine protected areas (Jones et al. 2004).

Recently spawned gametes of C. striatus are known to suffer high levels of predation (Robertson 1983). The damselfish Abudefduf vaigiensis was the focal egg predator species for the study since it is the dominant predator of C. striatus eggs at this study location. A. vaigiensis attack $70 \%$ of the gamete clouds released by C. striatus (authors' pers. obs.). Furthermore, a movement study of A. vaigiensis showed that most tagged individuals at FSASs and non-FSASs did not move greater than $40 \mathrm{~m}$, and the greatest movement observed was $<80 \mathrm{~m}$ (Fraser 2010). To determine whether differences in A. vai- 
giensis life-history traits resulted from the consumption of C. striatus eggs or another site-related effect, the lemon damselfish Pomacentrus moluccensis was used in comparison because this species is known not to consume C. striatus eggs (M.R. Fraser pers. obs.) and is relatively site attached (Beukers et al. 1995).

\section{Egg predation and fish collection}

Egg predation was quantified in October 2007 with behavioural observations at FSASs and non-FSASs during $C$. striatus spawning events. Scan observations of $A$. vaigiensis and $P$. moluccensis were performed by placing all individuals within an FSAS into 1 of several behavioural categories that represented their entire range of behaviours (Martin \& Bateson 1993): (1) feeding on eggs, (2) feeding on plankton, (3) swimming, and (4) all other minor behaviours including benthic feeding, interacting and hiding. Feeding on eggs was clearly distinguished when fish actively attacked visible gamete clouds near the water's surface. For A. vaigiensis at FSASs, scan observations were performed for the duration of a C. striatus spawning event ( $\mathrm{n}=30$ spawning events). At non-FSASs, scan observations were performed for the same duration when $C$. striatus spawning events were occurring at FSASs ( $\mathrm{n}=13$ spawning events). In the same way, scan observations for P. moluccensis were performed at FSASs $(\mathrm{n}=8)$ and non-FSASs $(\mathrm{n}=6)$.

During November 2007, fish were collected from each FSAS immediately after a C. striatus spawning event, when possible. However, for logistical reasons associated with spawning occurring at dusk, collections were also made the morning after a spawning event. Collections of $A$. vaigiensis ( $\mathrm{n}=59$ from FSASs and $\mathrm{n}=47$ from non-FSASs) and $P$. moluccensis ( $\mathrm{n}=$ 40 from FSASs and $n=39$ from non-FSASs) were made using a fence net and a dilute solution of clove oil, or a spear gun. All fishes were euthanized with an overdose of clove oil before the stomach was injected with exactly $0.1 \mathrm{ml}$ of buffered formalin and placed immediately on ice for no longer than $4 \mathrm{~h}$ prior to processing. Fishes were weighed $(0.01 \mathrm{~g})$ and measured $(0.1 \mathrm{~mm} ; A$. vaigiensis, fork length; P. moluccensis, standard length), and the head of each fish was removed and stored in $100 \%$ ethanol prior to removal of the otoliths for dry storage (for ageing purposes). The contents of the peritoneal cavity were removed and preserved in $10 \%$ buffered formalin. Analysis of stomach contents of A. vaigiensis from FSASs collected immediately after a C. striatus spawning event $(\mathrm{n}=4)$ revealed that fish eggs comprised 52 to $80 \%$ of the of the total stomach contents. However, too few $A$. vaigiensis were collected to provide meaningful statistical analysis.

\section{Growth, body condition and reproduction}

Ages of $A$. vaigiensis and $P$. moluccensis were determined by counting visible growth bands from transverse sections of sagittal otoliths. Otoliths were prepared following methods given by Wilson \& McCormick (1997). Growth bands have been validated as annual for a number of tropical pomacentrid species (Meekan et al. 1999). Therefore, growth bands in A. vaigiensis and $P$. moluccensis were assumed to be annual growth increments. Growth histories were determined with length versus age plots, and slopes were compared among FSASs and non-FSASs using analysis of covariance (ANCOVA). Length data were natural log transformed to meet assumptions of linearity, homogeneity of slopes and normality (Quinn \& Keough 2002).

The effects of egg predation on body condition were determined using 3 condition indices for both $A$. vaigiensis and $P$. moluccensis. An indication of the relative weight of a fish at the time of capture was determined using length versus eviscerated body weight plots. Slopes were compared between fish from FSASs and non-FSASs using ANCOVA. Length data were natural log transformed to meet assumptions of ANCOVA. The relative weight of the liver, (hepatosomatic index, HSI) and liver vacuolation were also determined to yield measures of physiological condition. Preserved livers were weighed to the nearest $0.01 \mathrm{~g}$, and HSI was determined using the formula HSI $=\mathrm{WL} \times 100 / \mathrm{WB}$, where $\mathrm{WL}$ is preserved liver weight and WB is gutted body weight (McCormick 2003). Liver vacuolation in fishes is indicative of lipid and glycogen storage within the liver (Green \& McCormick 1999, Pratchett et al. 2004, Hoey et al. 2007). To quantify liver vacuolation, livers were prepared histologically following the methodology of Hoey et al. (2007). Two $5 \mu \mathrm{m}$ sections were taken from each of the anterior, middle and posterior portions of each liver. The proportion of hepatocyte vacuolation from each section was determined with a Weibel eyepiece by recording the proportion of points that intersected (out of 121) with vacuoles at $40 \times$ magnification. Raw data analysed were the mean values of the 6 estimates of liver vacuolation from each fish. For each species, HSI data were compared among FSASs and non-FSASs using 1-factor 
ANOVA. Data were examined for homogeneity of variance using residual analysis (Quinn \& Keough 2002).

Reproductive state of female $A$. vaigiensis and $P$. moluccensis at capture were determined using the relative weight of the gonad (gonadosomatic index, GSI). The state of maturation of preserved ovaries was visually assessed and ovaries were weighed. Ovary weight was divided by eviscerated body weight to give GSI. The equality of mean GSI values from FSASs and non-FSASs were examined for both species using 1-factor ANOVA.

\section{RESULTS}

\section{Egg predation}

Only Abudefduf vaigiensis at FSASs fed actively on eggs during Ctenochaetus striatus spawning events (Fig. 1). A total of $88 \%$ A. vaigiensis (of 834 individuals) fed on eggs within visible gamete clouds, while no A. vaigiensis (of 125 individuals) observed at non-FSASs fed on eggs during the same period. As a consequence of this difference in foraging behaviour, a smaller proportion of the time budget of $A$. vaigiensis behaviour was spent swimming $(6.6 \%)$ and feeding on plankton $(5.1 \%)$ at FSASs during C. striatus spawning aggregations. A. vaigiensis at FSASs spent $61.9 \%$ more time feeding on eggs and plankton compared to fish at non-FSASs. In contrast, Pomacentrus moluccensis were never observed feeding on eggs at FSASs (92 fish) or non-FSASs (61 fish; Fig. 1).

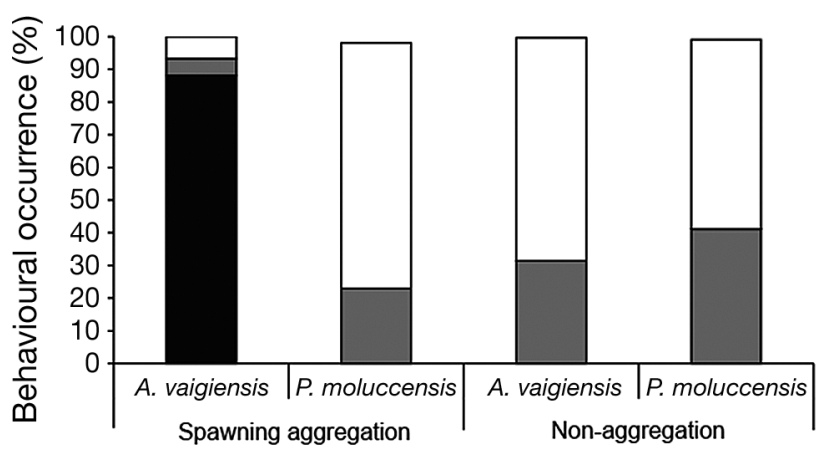

Fig. 1. Mean occurrence of behaviours of Abudefduf vaigiensis and Pomacentrus moluccensis at fish spawning aggregation sites and similar non-aggregation sites during periods of Ctenochaetus striatus spawning. Behavioural categories: black, feeding on gamete clouds; grey, feeding on plankton; white, swimming

\section{Body condition}

Length versus weight relationships did not differ for female (ANCOVA, $F_{1,44}=2.748, \mathrm{p}=0.104$ ) or male (ANCOVA, $\left.F_{1,24}=3.145, \mathrm{p}=0.088\right)$ A. vaigiensis between FSASs and non-FSASs. Similarly, there was no significant difference in the relative body condition of female (ANCOVA, $F_{1,24}=0.345 ; \mathrm{p}=0.557$ ) and male (ANCOVA, $\left.F_{1,12}=0.088 ; \mathrm{p}=0.771\right)$ P. moluccensis between FSAS and non-FSASs.

Hepatocyte vacuolation of the livers from $A$. vaigiensis differed between FSASs and non-FSASs for females $\left(F_{1,26}=13.787, \mathrm{p}<0.001\right)$ and males $\left(F_{1,19}=\right.$ 6.5718, $\mathrm{p}=0.019$; Fig. 2), with fish from FSASs having more than double the levels of vacuolation compared to those from non-aggregation sites. In contrast, there was no difference in the hepatocyte vacuolation for $P$. moluccensis females $\left(F_{1,33}=0.322\right.$, $\mathrm{p}=0.527)$ or males $\left(F_{1,12}=1.181, \mathrm{p}=0.298\right)$ between FSASs and non-FSASs.

Despite the difference in vacuolation, there was no difference in HSI between FSASs and non-FSAS for female $\left(F_{1,18}=4.091, \mathrm{p}=0.058\right)$ or male $\left(F_{1,21}=2.582\right.$, $\mathrm{p}=0.123)$ A. vaigiensis. Likewise, female and male $P$. moluccensis also did not differ in HSI between FSAS and non-FSASs (females: $F_{1,20}=1.726, \mathrm{p}=$ 0.203; males: $F_{1,12}=0.275, \mathrm{p}=0.609$ ).

\section{Growth}

The A. vaigiensis collected at the present study location were remarkably short-lived, with ages ranging from 2 to 4 yr (see Figs. 3 \& 4). Despite managing to collect only relatively small sample sizes of males from FSASs and non-FSASs (15 and 11, respectively), male $A$. vaigiensis at FSASs had significantly faster growth compared to males from non-

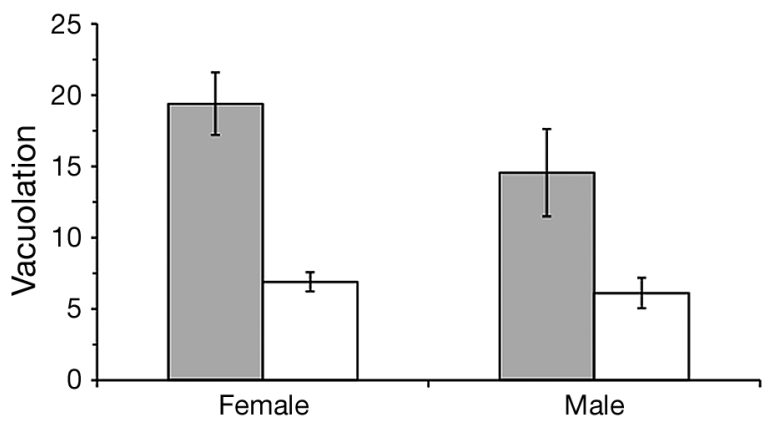

Fig. 2. Liver hepatocyte vacuolation (mean $\% \pm \mathrm{SE}$ ) of female and male Abudefduf vaigiensis from spawning aggregations sites (grey) and similar non-aggregation sites (white) 
FSASs (ANCOVA, $F_{1,24}=6.156, \mathrm{p}=0.021$; Fig. 3 ). The difference in growth was predominantly due to higher growth early in life (Year 2), with the older (Years 3 and 4) age-classes being of a similar length. No significant difference was found in the growth histories of female $A$. vaigiensis among FSASs and non-FSASs (ANCOVA, $F_{1,50}=3.311, \mathrm{p}=0.075$ ). The growth histories of male (ANCOVA, $F_{1,24}=0.747, \mathrm{p}=$ 0.396 ) and female (ANCOVA, $F_{1,12}=0.391, \mathrm{p}=0.544$ ) $P$. moluccensis did not differ significantly between FSASs and non-FSASs.

\section{Reproduction}

Female A. vaigiensis from FSASs had larger ovaries relative to body weight (GSI) than females from nonFSASs $\left(F_{1,49}=4.861, \mathrm{p}=0.032\right.$; Fig. 4$)$, despite ovaries having a range of reproductive states from both locations, ranging from stage 1 to stage 3 . In comparison, GSI in male $A$. vaigiensis did not differ between FSASs and non-FSASs $\left(F_{1,25}=0.665, \mathrm{p}=0.422 ;\right.$ Fig. 4$)$. The mean GSI of female $\left(F_{1,21}=0.489, \mathrm{p}=0.492\right)$ and male $\left(F_{1,10}=1.207, \mathrm{p}=0.298\right) P$. moluccensis also did not differ among FSAS and non-FSASs.

\section{DISCUSSION}

Identifying sources of variation in food availability on coral reefs and how reef fishes make trade-offs in energy allocation between growth and reproduction

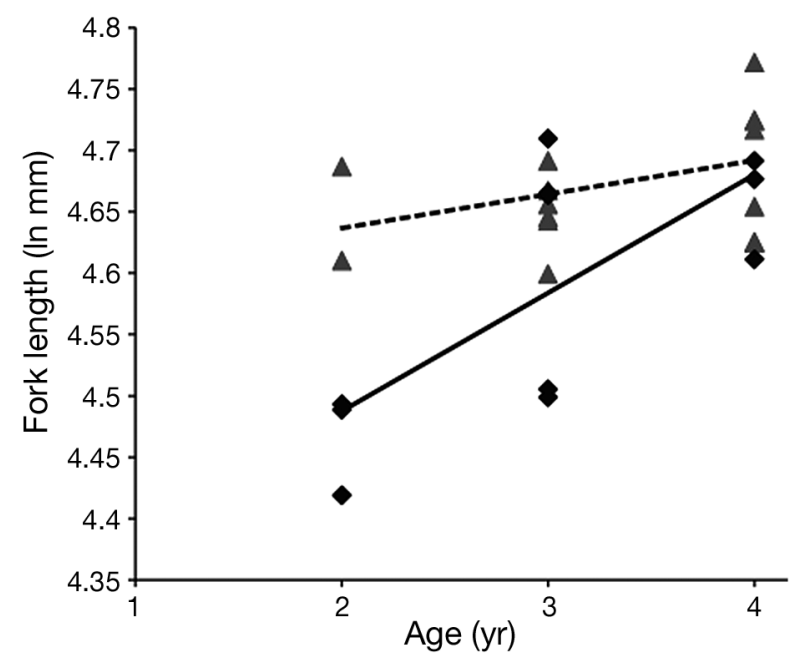

Fig. 3. Growth relationships of male Abudefduf vaigiensis collected from fish spawning aggregations sites (triangles and dashed line, $\mathrm{n}=15$ ) and similar non-aggregation sites (diamonds and solid line, $\mathrm{n}=11$ ). Fork length is displayed as a natural logarithm

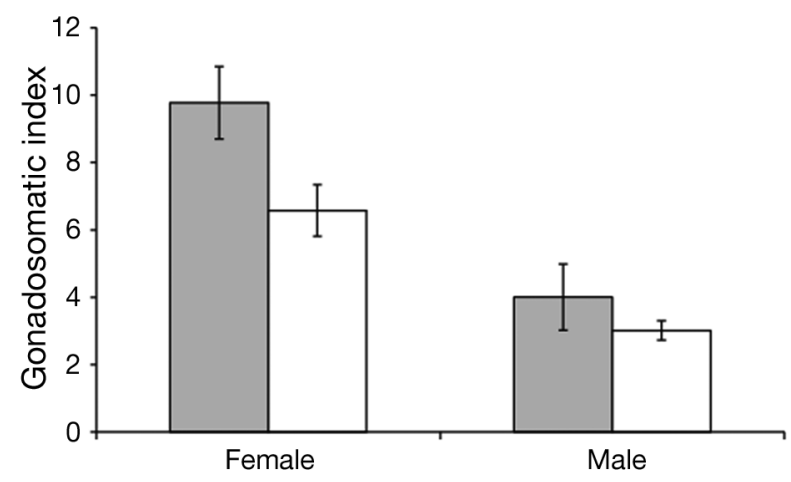

Fig. 4. Gonadosomatic index of female and male Abudefduf vaigiensis from fish spawning aggregation sites (grey) and similar non-aggregation sites (white). Error bars are $\pm \mathrm{SE}$

is fundamental to understanding population dynamics. Observations of egg predation at FSASs has prompted the suggestion that egg predators benefit energetically from consuming eggs at FSASs (Heyman et al. 2001), but our study is the first to quantitatively examine the energetic effects of this trophic link. Feeding on this rich source of energy benefited the egg predator, but how these benefits were realised was gender-specific. While egg predation did not influence overall body condition or bulk of $\mathrm{Abu}$ defduf vaigiensis, both males and females stored more energy products in their liver vacuoles. From there, males allocated excess energy to growth, while females allocated greater energy to current reproduction. This study underscores the importance of eggs as a food source for the egg-predator community and highlights the potential benefits that capitalising on this predictable, pulsed resource to local reproductive output and life-history strategies of the egg predator community.

Theory predicts that trade-offs in energy allocation between growth and reproduction evolved to maximise reproductive success over an individual's expected lifetime (Stearns 1992). Our findings show that males that fed on eggs allocated more energy to growth, while their investment in gametes (quantified here as GSI) remained similar to fishes that did not feed on eggs. Body size is a key determinant of superiority in many aspects of performance and ecology for many organisms (Okie et al. 2013). Size is often a strong predictor of dominance and with that, preferential access to resources, mating opportunities and hence fitness. Females can give mating preference to larger males (Cote \& Hunte 1989, Cole \& Sadovy 1995), and larger nest-guarding males often have higher clutch survivorship (Cote \& Hunte 1989). Our data suggest that male $A$. vaigiensis may trade 
immediate investments in reproductive products for size-dependent, socially-mediated future reproductive success. In addition, size is closely linked with age of reproduction in reef fishes (Jones \& McCormick 2002). Therefore, male A. vaigiensis that have access to eggs as a food resource may also reach sexual maturity at a younger age, potentially giving them more breeding opportunities during their short lifespans. Collectively, our data suggest that male A. vaigiensis from FSASs may effectively contribute more to the breeding population than conspecifics elsewhere.

In contrast to males, females allocated greater energy to current reproduction relative to females that did not consume eggs. Our results suggest that female $A$. vaigiensis trade an immediate increase in egg production against accelerated growth in body size, and therefore an immediate increase in egg production rather than a greater fecundity associated with larger female size (Maddams \& McCormick 2012). Because increases in body size may also mitigate the risk of predation (Sogard 1997), females may also trade potentially lower rates of mortality for immediate reproductive investment. The reason for this strategy may be explained by the extended breeding season and short reproductive life span of A. vaigiensis at this study site. A previous study at the same low latitudinal study reefs showed that damselfishes have extended breeding seasons spanning 6 mo that coincide with the dry season (Srinivasan \& Jones 2006). In addition, our study shows that $A$. vaigiensis have a relatively short life span of 4 yr compared to over 20 yr for similar Pomacentrid species from cooler latitudes (Fowler \& Doherty 1992, Meekan et al. 2001). Our study highlights how sexspecific life-history strategies can influence the utilisation of energy obtained from natural fluctuations in food availability and ultimately alter demographic parameters.

Energy that is allocated to reproduction can be used to produce more gametes of a similar quality, place more energy into each gamete, or a combination of both (Marshall \& Uller 2007). Unfortunately, the offspring of egg predators could not be obtained in the present study, so which option was adopted at the studied FSASs is unknown. McCormick (2003) found that ambon damselfish Pomacentrus amboinensis that switched to feeding on coral spawn during the annual mass spawning produced the same number of embryos, but these hatched with $25 \%$ larger yolk sacs and $100 \%$ larger oil globules. The eggs consumed by damselfish at FSASs have the exact nutrient profile necessary for their own repro- duction and are rich in essential fatty acids and amino acids capable of influencing fecundity and maternal provisioning (Sargent et al. 1999). Increased essential nutrients enhance reproduction and maternal provisioning in the natural diets of the zebra finch Taeniopygia guttata (Royle et al. 2003), and the limitation of essential nutrients has been proposed to describe patterns in reproduction in wrasses Thalassoma bifasciatum (Schultz \& Warner 1991). The finding of improved offspring provisioning with increased pre-spawning maternal conditioning is common among a wide range of organisms (Bernardo 1996, Green 2008). Regardless of whether $A$. vaigiensis in the present study produces higherquality or more offspring as a result of feeding on eggs released at spawning sites, it is likely that this nutritious and predictable food source leads to a valuable reproductive benefit to those fish that are willing to exploit it.

In summary, this study shows that natural variations in food supply influence demographic parameters in reef fish. Given the regular nature of this high-energy food resource (Claydon et al. 2014), eggs released at spawning sites appear to represent an important energy source that has beneficial repercussions for the individuals that exploit it. This study suggests that males grow faster and females put more energy into reproduction. Given the demonstrated beneficial effects of advantages in early development to subsequent developmental trajectories, growth, performance, fitness and survival (e.g. Gagliano et al. 2007, Walker et al. 2007, McCormick et al. 2010), it is likely that egg predators feeding at FSASs will make a greater contribution to the next generation for their species at the cost of the species aggregating to spawn. If this is the case, then the periodicity in spawning intensity at spawning sites (and hence egg predation) may influence the periodicity of recruitment of egg predator juveniles through enhanced larval survival. Over the last 2 decades, the protection of FSASs from harvest has been promoted as a broadly applicable management strategy to avoid the overexploitation of many commercially important species, particularly serranids (Claydon 2004, Sadovy \& Domeier 2005, Russell et al. 2012). The current findings highlight that protecting spawning aggregations will also benefit trophically linked reef fishes, with important consequences for the resilience of associated reef species.

Acknowledgements. Research funding was provided by the Australian Research Council Centre of Excellence for Coral Reef Studies. We thank M. Bird for valuable assistance with field work. We thank residents of Kilu and Tamare villages 
for allowing access to their reefs. This research was supported by Mahonia Na Dari Research and Conservation Centre and $\mathrm{M}$. and C. Benjamin of Walindi Plantation Resort. Research was undertaken in accordance with the animal ethics guidelines for James Cook University. The study is in compliance with the present laws of Papua New Guinea.

\section{LITERATURE CITED}

Bernardo J (1996) The particular maternal effect of propagule size, especially egg size: patterns, models, quality of evidence and interpretations. Am Zool 36:216-236

Beukers JS, Jones GP, Buckley RM (1995) Use of implant microtags for studies on populations of small reef fish. Mar Ecol Prog Ser 125:61-66

Claydon JAB (2004) Spawning aggregations of coral reef fishes: characteristics, hypotheses, threats and management. Oceanogr Mar Biol Annu Rev 42:265-302

Claydon JAB (2005) The structure and dynamics of spawning aggregations of coral reef fish. PhD thesis, James Cook University, Townsville

Claydon JAB, McCormick MI, Jones GP (2012) Patterns of migration between feeding and spawning sites in the tropical surgeonfish. Coral Reefs 31:77-87

Claydon JAB, McCormick MI, Jones GP (2014) Multi-species spawning sites for fishes on a low latitude coral reef: spatial and temporal patterns. J Fish Biol 84:1136-1163

Clifton KE (1995) Asynchronous food availability on neighboring Caribbean coral reefs determines seasonal patterns of growth and reproduction for the herbivorous parrotfish Scarus iserti. Mar Ecol Prog Ser 116:39-46

Cole KS, Sadovy Y (1995) Evaluating the use of spawning success to estimate reproductive success in a Caribbean reef fish. J Fish Biol 47:181-191

Cote IM, Hunte W (1989) Male and female mate choice in the redlip blenny - why bigger is better. Anim Behav 38: 78-88

Domeier ML, Colin PL (1997) Tropical reef fish spawning aggregations: defined and reviewed. Bull Mar Sci 60: 698-726

$>$ Forrester GE (1990) Factors influencing the juvenile demography of a coral reef fish. Ecology 71:1666-1681

Fowler AJ, Doherty PJ (1992) Validation of annual growth increments in the otoliths of two species of damselfish from the Southern Great Barrier Reef. Aust J Mar Freshw Res 43:1057-1068

Fraser MR (2010) Egg predation at tropical reef fish spawning aggregation sites: trade-offs for fitness. PhD thesis, James Cook University, Townsville

Gagliano M, McCormick MI, Meekan MG (2007) Survival against the odds: ontogenetic changes in selective pressure mediate growth-mortality tradeoffs. Proc R Soc Lond B Biol Sci 274:1575-1582

> Green BS (2008) Maternal effects in fish populations. Adv Mar Biol 54:1-105

> Green BS, McCormick MI (1999) Influence of larval feeding history on the body condition of Amphiprion melanopus. J Fish Biol 55:1273-1289

> Gust N, Choat JH, Ackerman JL (2002) Demographic plasticity in tropical reef fishes. Mar Biol 140:1039-1052

> Heyman WD, Graham RT, Kjerfve B, Johannes RE (2001) Whale sharks Rhincodon typus aggregate to feed on fish spawn in Belize. Mar Ecol Prog Ser 215:275-282
Hoey J, McCormick MI, Hoey AS (2007) Influence of depth on sex-specific energy allocation patterns in a tropical reef fish. Coral Reefs 26:603-613

> Jones GP (1986) Food availability affects growth in a coral reef fish. Oecologia 70:136-139

Jones GP, McCormick MI (2002) Numerical and energetic processes in the ecology of coral reef fishes. In: Sale PF (ed) Coral reef fishes - dynamics and diversity in a complex ecosystem. Academic Press, London, p 221-238

> Jones GP, McCormick MI, Srinivasan M, Eagle JV (2004) Coral decline threatens fish biodiversity in marine reserves. Proc Natl Acad Sci USA 101:8251-8253

Kamler E (1992) Early life history of fish: an energetics approach, Vol 4. Chapman \& Hall, London

Krebs CJ (1994) Ecology - the experimental analysis of distribution and abundance. HarperCollins College Publishers, New York, NY

Maddams JC, McCormick MI (2012) Not all offspring are created equal: variation in larval characteristics in a serially spawning damselfish. PLoS ONE 7:e48525

Marshall DJ, Uller T (2007) When is a maternal effect adaptive? Oikos 116:1957-1963

Martin P, Bateson P (1993) Measuring behaviour — an introductory guide. Cambridge University Press, Cambridge

May RM (1972) Limit cycles in predator-prey communities. Science 177:900-902

> McCormick MI (2003) Consumption of coral propagules after mass spawning enhances larval quality of a damselfish through maternal effects. Oecologia 136:37-45

> McCormick MI, Ryen CA, Munday PL, Walker SPW (2010) Differing mechanisms underlie sexual size-dimorphism in two populations of a sex-changing fish. PLoS ONE 5: e10616

Meekan M, Wellington G, Axe L (1999) El Niño-Southern Oscillation events produce checks in the otoliths of coral reef fishes in the Galápagos Archipelago. Bull Mar Sci 64:383-390

> Meekan MG, Ackerman JL, Wellington GM (2001) Demography and age structures of coral reef damselfishes in the tropical eastern Pacific Ocean. Mar Ecol Prog Ser 212:223-232

Nemeth RS (2012) Ecosystem aspects of species that aggregate to spawn. In: Sadovy de Mitcheson Y, Colin PL (eds) Reef fish spawning aggregations: biology, research and management. Fish and Fisheries Series Vol 35. Springer, Dordrecht, p 21-55

> Okie JG, Boyer AG, Brown JH, Costa DP and others (2013) Effects of allometry, productivity and lifestyle on rates and limits of body size evolution. Proc R Soc Lond B Biol Sci 280:20131007

Pears R, Nemeth RS, Ferreira BP, Hostim-Silva M and others (2012) Species case studies. In: Sadovy de Mitcheson Y, Colin PL (eds) Reef fish spawning aggregations: biology, research and management. Fish and Fisheries Series Vol 35. Springer, Dordrecht, p 405-565

> Pratchett MS, Wilson SK, Berumen ML, McCormick MI (2004) Sub-lethal effects of coral bleaching on an obligate coral feeding butterflyfish. Coral Reefs 23: 352-356

Quinn GP, Keough MJ (2002) Experimental design and data analysis for biologists. Cambridge University Press, Cambridge

Randall JE (1961) Observations on the spawning of surgeonfishes (Acanthuridae) in the Society Islands. Copeia 1961:237-238 
Robertson DR (1983) On the spawning behavior and spawning cycles of eight surgeonfishes (Acanthuridae) from the Indo-Pacific. Environ Biol Fishes 9:193-223

Roff D (1984) The evolution of life history parameters in teleosts. Can J Fish Aquat Sci 41:989-1000

Royle NJ, Surai PF, Hartley IR (2003) The effect of variation in dietary intake on maternal deposition of antioxidants in zebra finch eggs. Funct Ecol 17:472-481

Russell MW, Luckhurst BE, Lindeman KC (2012) Management of spawning aggregations. In: Sadovy de Mitcheson Y, Colin PL (eds) Reef fish spawning aggregations: biology, research and management. Fish and Fisheries Series Vol 35. Springer, Dordrecht, p 371-404

Sadovy Y, Domeier M (2005) Are aggregation-fisheries sustainable? Reef fish fisheries as a case study. Coral Reefs 24:254-262

Sancho G, Petersen CW, Lobel PS (2000) Predator-prey relations at a spawning aggregation site of coral reef fishes. Mar Ecol Prog Ser 203:275-288

Sano M, Shimizu M, Nose Y (1984) Food habits of teleostean reef fishes in Okinawa Island, Southern Japan. Univ Mus Univ Tokyo Bull 25:1-128

Editorial responsibility: Nicholas Tolimieri, Seattle, Washington, USA
Sargent JR, Bell JG, McEvoy L, Tocher DR, Estevez A (1999) Recent developments in the essential fatty acid nutrition of fish. Aquaculture 177:191-199

Schultz ET, Warner RR (1991) Phenotypic plasticity in life history traits of female Thalassoma bifasciatum (Pisces: Labridae): 2. Correlation of fecundity and growth rate in comparative studies. Environ Biol Fishes 30:333-344

Sogard SM (1997) Size-selective mortality in the juvenile stage of teleost fishes: a review. Bull Mar Sci 60: 1129-1157

Srinivasan M, Jones GP (2006) Extended breeding and recruitment periods of fishes on a low latitude coral reef. Coral Reefs 25:673-682

Stearns SC (1992) The evolution of life histories. Oxford University Press, Oxford

Walker SPW, Ryen CA, McCormick MI (2007) Rapid larval growth promotes sex change and growth acceleration in a protogynous hermaphrodite, Parapercis snyderi Jordan \& Starks 1905. J Fish Biol 71:1347-1357

Wilson DT, McCormick MI (1997) Spatial and temporal validation of settlement-marks in the otoliths of tropical reef fishes. Mar Ecol Prog Ser 153:259-271

Submitted: June 16, 2014; Accepted: August 25, 2014 Proofs received from author(s): December 2, 2014 